\title{
Resenha
}

Yaneva, Albena. Mapping Controversies in Architecture. Surrey, Ashgate, 2012, 128pp.

\section{A ontologia maleável do concreto}

\author{
Guilherme Giufrida \\ Universidade Federal do Rio de Janeiro
}

O procedimento metodológico fundamental defendido por Albena Yaneva em Mapping Controversies in Architecture é a tradução e a extensão do conceito de cartografia das controvérsias para o estudo e crítica de arquitetura. A autora trata a arquitetura (e, brevemente, o design e o urbanismo) como processo, buscando escapar da clássica oposição - segundo ela, principalmente dos historiadores da arte - entre formalismo e historicismo, propondo um estudo pragmático e radicalmente empírico da construção de edifícios.

Para tanto, questiona uma série de polarizações "modernistas" - como função e significado, forma e conteúdo, técnica e arte, tecnologia e sociedade, objetivo e subjetivo, material e simbólico, natureza e cultura - constantes na maneira como, segundo ela, a arquitetura é pesquisada. Pretende, assim, desfazer essa divisão específica do mundo, já questionada pela antropologia, que, ao separar os aspectos tecnológicos dos políticos, produz regras de causalidades específicas.

Segundo Yaneva, o construtivismo social dominou a sociologia nos anos 1970 e 1980, defendendo tanto que a sociedade produz prédios, como que os prédios ajudam a manter formas sociais. O "social" foi tratado por essa sociologia como domínio separado com atributo de causalidade e capacidade de dar solidez, durabilidade e consistência à arquitetura.

Yaneva critica, em especial, a análise de Pierre Bourdieu sobre a casa berber dos Kabyla, povo que vive no norte da Argélia ${ }^{1}$. Neste texto, Bourdieu defende não ser possível uma análise técnica para entender o modo de vida daquele povo, por isso propõe decifrar os significados e práticas escondidos por trás de suas edificações - por exemplo, a divisão 
do espaço refletiria sua divisão do trabalho. Não há na análise de Bourdieu, segundo Yaneva, menção a materiais, formas de construir ou tecnologias, isto é, o autor recusa considerar os aspectos técnicos e materiais de compartilhar o mundo berbere, prevalecendo os aspectos "simbólicos". Para Bourdieu, a descoberta dos "subtextos" das edificações daria sentido ao desenho da casa, que não só reflete como reproduz as oposições internas daquela sociedade. Assim, analisa o "social" como um contexto expressado na arquitetura.

Yaneva questiona Bourdieu por sua tentativa de explicar a casa berbere sem detalhar como foi feita, e por estabilizar diferenças reveladas na estrutura de uma casa, almejando alcançar a explicação de toda uma sociedade. A autora discorda do determinismo social bourdiano, especialmente por trabalhar com elementos sociais (classe, gênero, símbolos, mitos e crenças) e os não sociais (grades, paredes, portas), em que à arquitetura restaria o papel de efeito. Yaneva chama atenção, dialogando com Bruno Latour, que se deve ter claro que as ciências sociais fazem parte do problema e das questões que estamos estudando, mas não são a solução ${ }^{2}$.

A autora também critica análises que se centram em mostrar como os prédios influenciam as sociedades. O exemplo clássico são as prisões: uma arquitetura que transforma baseada na vigília e no controle, e um instrumento de estabilização da ordem social. A autora defende que a arquitetura age, mas, questionando Michel Foucault, critica o estabelecimento de relações de causa-efeito ${ }^{3}$. Nesse caso, a arquitetura seria o elemento conhecido que gera modificações na sociedade. A crítica foucaultiana se limita, para Yaneva, a compreender a arquitetura em sua relação instrumental com a sociedade, defendendo que prédios são um mecanismo de exercer controle (pois o poder estaria investido nas coisas). Mas, não há discussão sobre a construção, tecnologias e outras questões cruciais de desenho, porque a materialidade é tratada como passiva, neutra e inerte. Foucault, para Yaneva, assim como Bourdieu, persiste distanciando o significado da materialidade e dos desafios do processo de construção, ou seja, distinguindo o "tecnológico" e o "social".

Por fim, Yaneva também se opõe à influência da Escola de Frankfurt sobre a crítica de arquitetura. Para essa escola, o papel dos edifícios seria, segundo a autora, o de desvelar os mecanismos, constrangimentos, representações, princípios e forças escondidos que impedem a sociedade de encontrar seu rumo mais justo. Ou seja, ao se atentar às condições sócio-históricas, culturais e econômicas na produção da arquitetura e no seu conhecimento, os frankfurtianos pretendem, segundo Yaneva, produzir uma reflexão sobre os limites, condições e possibilidades do conhecimento no capitalismo, em busca de imaginação e 
construção de alternativas de como a arquitetura poderia resistir. No entanto, a teoria crítica da arquitetura interpreta a produção de edifícios em busca de símbolos para tratá-los como produção cultural e também desvelar os seus significados sociais. Assim, as características físicas seriam signos a serem revelados pela crítica, criando, segundo Yaneva, uma espécie de mito em torno do trabalho do arquiteto.

Yaneva é contrária à ideia de que haveria sentidos por trás dos edifícios, por isso, critica a abordagem semiótica, que procura interpretar aquilo que estaria subentendido na arquitetura. Para a autora, o sentido não está fora dos edifícios e não pertence a sujeitos atentos ou treinados; assim como a conjuntura social e política não define o sucesso ou fracasso de uma arquitetura; tampouco a arquitetura é simplesmente um instrumento de controle. Em outras palavras, para ela, a arquitetura não é espelho de uma sociedade, nem reflete a situação econômica ou conforma a sociedade de uma determinada maneira.

As ideias sobre sociedade receberam novas contribuições nas últimas décadas criticando a teoria social que toma por garantido o que seja sociedade, privilegiando a socialidade e a invenção. A análise de Yaneva estabelece diálogo estreito com Bruno Latour - de quem foi aluna no doutorado e com quem já escreveu um artigo sobre arquitetura ${ }^{4}$ sobretudo em Reassembling the Social, obra na qual o autor propõe substituir a "sociologia do social" por uma "sociologia das associações". Se o "social" for compreendido como verbo (ação de conexão), a arquitetura é uma reunião de associações e controvérsias entre atores desenhando um projeto. Um processo performado por uma textura de incertezas. Por isso, segundo Yaneva, não podemos tratar a arquitetura como um procedimento impessoal ou atribuí-la a uma única personalidade. A construção, defende, é a dinâmica de modificação coletiva para a composição de edificações em que pressupostos científicos (ou técnicos) são criados e destruídos continuamente.

Yaneva propõe mapear quais os atores envolvidos no processo de desenhar e construir um projeto de arquitetura, e quão diferentes são suas vozes e ações transformativas. Para ela, o prédio não é uma entidade estática composta de símbolos, mas um fluxo de trajetórias e dramatizações do desenho e da construção, por isso, devem interessar para o pesquisador, sobretudo, as discordâncias, preocupações, composição de forças e eventos, as divergências sobre materiais e os acidentes da construção. A arquitetura, a partir dessa aproximação que ela chama de "etnográfica", deixaria de ser pensada como a forma de um significado, e mais como mapa dessas trajetórias; liberandose, pois, da condição de uma materialidade estável, e se afirmando como uma fábrica em transformação. 
A autora defende uma abordagem não representacional da arquitetura. A interpretação representacional dependeria de um edifício congelado, como um totem, em que os materiais refletem e expressam símbolos fixos. No entanto, para Yaneva, não há necessidade de fixar categorias, estilos e etiquetas; pois a qualidade do edifício é conquistada no seu processo de interações anteriores, durante e posteriores à construção. Em certo momento do livro indica que, se aceitarmos o regime não representacional para estudar a arquitetura, devemos, sobretudo, nos perguntar: o que um prédio faz?

O centro da proposta de Yaneva, que dá título ao livro, é a tradução e a extensão da cartografia das controvérsias para a análise da arquitetura. As controvérsias são, nos termos de Michel Callon, fóruns híbridos, espaços de negociações e conflitos entre atores humanos e não-humanos (no caso da arquitetura: o telhado, o escritório do arquiteto, as regras de uma competição). Controvérsias em arquitetura são as incertezas que envolvem um projeto e as situações de discordância que atravessam esses atores que participam da obra ${ }^{6}$. Yaneva conclama o pesquisador a acompanhar o fluxo dos eventos do processo de fazer o edifício, já que, para ela, só através da disputa de eventos é possível reconstruir como um prédio foi feito. A autora condena quem ainda representa os edifícios como objetos estáticos, e por isso combate a análise da arquitetura por fotografias, como se ela fosse apenas questão de espaço, e defende a abordagem etnográfica, pois é só através dela que somos capazes de introduzir a dimensão do tempo na análise.

No livro, como forma de exemplificar brevemente sua defesa metodológica, Yaneva discorre sobre alguns projetos de arquitetura, especialmente sobre a maneira como foram viabilizados e as diversas reações do público ao prédio pronto. Por exemplo, comenta o concurso público realizado para a construção do edifício sede do Parlamento de Cardiff, cidade que recebeu em 1955 o título de capital do País de Gales. Em um movimento de criar identidade própria ao povo galês, houve uma competição para a construção do edifício de seu Parlamento que deveria, segundo o que Yaneva pesquisou, "resumir a nação". O júri se atentou ao detalhamento "técnico" dos projetos, em especial, sobre como encontrar soluções, através de tecnologias e de materiais, para resolver as dificuldades provocadas pela geologia do local em que se instalaria o edifício. Yaneva sublinha o foco do júri em considerar o projeto que melhor detalhasse quais técnicas deveriam ser convocadas para inventar uma nação.

Yaneva revisita também a controvérsia alemã sobre a reforma do Reichstag nos anos 1990, sede do Parlamento alemão, que teria que simbolizar a democracia, a reunião das duas Alemanhas, e uma renovação na história do país. A autora analisa especialmente a 
escolha do vidro para o novo domo e os debates sobre a sua transparência e fragilidade. Qual dessas particularidades do vidro iria melhor representar a democracia alemã? A resposta da autora é de que cabe aos atores interagindo com outro ator não-humano, o prédio, construir qual democracia poder ser acionada a partir daquele novo domo de vidro.

Os entrevistados de Yaneva ressaltam, assim, a necessidade de conciliar simbolismo e funcionalidade, aspectos negociados constantemente durante a construção. A autora observa os efeitos da escolha de materiais em engajar o simbolismo, o que pode ser analisado desde o projeto até as mais diversas reações à produção de um espaço. Defende que simbolismo e significado são recriados por funcionalidade e eficiência através de uma narrativa tecnológica performada. Por isso, segundo Yaneva, não devemos continuar a representar os edifícios como partes técnicas resultantes de um desenho que permanece inerte no tempo.

O desenho é um dos agentes do processo de edificação. Mas a autora defende que as formas, texturas e reações imprevisíveis dos materiais reformulam os problemas do arquiteto, que "reflete enquanto faz". Yaneva usa o conceito de "materiologia" (que diz trazer dos autores Gilbert Simondon e Étienne Souriau) para dar conta da materialidade poética dos objetos, suas surpresas, os gestos pelos quais os materiais são usados, as consequências não previstas e suas características subestimadas. Como afirma, "para a pluralidade do simbólico devemos adicionar a multiplicidade do material” (pp. 19), ou seja, o próprio material não é encontrado em apenas uma condição, é variável e imprevisível. Assim, segundo ela, ver-se-á que os prédios não são feitos por mentes poderosas, tampouco são feitos para simbolizar, mas sim são processos frágeis e vulneráveis à matéria que lhes dá forma.

Devemos questionar o que torna o edifício possível, pois não se trata de um projeto pronto entregue pelo arquiteto para o engenheiro realizar, como experts solitários, mas sim um trabalho coletivo sobre as restrições técnicas e inovações tecnológicas que possibilitam a construção. Por isso, para Yaneva, as controvérsias que envolvem a construção de um edifício são concretas, aproveitando-se do duplo-sentido do termo: o material básico da construção dos edifícios modernos e a noção do que é real ou objetivo. O edifício é uma materialidade provisória das incorporações de relações entre agentes e controvérsias sobre os materiais usados para construí-lo. O concreto impregnado na arquitetura contém uma série de rituais e práticas que permitiram um certo tipo 
participação no mundo criadas nos processos de edificação, mas que permanecem dinâmicas a inúmeras apropriações.

Prédios, segundo a autora, só podem ser compreendidos sob um meticuloso estudo de suas maneiras específicas de ganhar corpo, e dos mundos que podem gerar. A pesquisa etnográfica evita, defende Yaneva, isolar a arquitetura das outras conexões com o mundo, já que o pesquisador se ocupa em mobilizar tecnologias e humanidades (isto é, sem distinção entre agentes não-humanos e humanos) para de fato seguir os atores, suas visões de mundo, percebê-los como entidades heterogêneas e descrever o que acontece nessas situações, em geral de extrema volatilidade. A autora usa vastamente o conceito de rede, pois defende que os fenômenos da arquitetura devem ser observados a partir de diversos pontos de vista, sem o objetivo de mostrar aquilo que os atores não foram capazes de ver, mas aprender com todos eles como observar as existências coletivas dos agentes e seus efeitos na construção e recepção da arquitetura.

Neste "novo mundo" (em tom crítico à maneira que a arquitetura costuma ser estudada) produzido pelo cartógrafo (ou etnógrafo), Yaneva sublinha que os prédios assumiriam sua característica de agentes; e os outros atores passariam a ganhar suas identidades em disputa, seriam todos redes. O processo de cartografia das controvérsias em arquitetura solidifica um amálgama líquido dos processos em um nível concreto das ligações entre os edifícios e o mundo pensados em estado sólido (ou concreto), mesmo que não estabilizado (ou maleável).

Yaneva também defende que o trabalho do etnógrafo esteja em consonância com a matéria que estuda, a arquitetura. Por isso, argumenta a favor do uso de novas tecnologias, utilizadas usualmente em escritórios de design. O desenho pós-paramétrico é a solução proposta por Yaneva, pois, segundo ela, através dele é possível estabelecer um mapa dinâmico de agentes, em que as condições de possibilidade de cada um deles são instáveis e flexíveis. Através dessa ferramenta é possível contemplar as novidades percebidas em cada nova etapa da cartografia das controvérsias. Além disso, o design pós-paramétrico possibilita que se desenhem as controvérsias em movimento e a fragilidade das práticas de conhecimento e das redes colaborativas criadas pela arquitetura, pois possibilita que se criem redes que não disponham das identidades prévias definidas dos atores.

Portanto, a partir de métodos e estratégias que ligam a pesquisa etnográfica de controvérsias a mapeamentos dinâmicos fornecidos por ferramentas do design, Albena Yaneva, busca, neste livro, apresentar sua proposta para estudar a arquitetura. A autora se diz uma empirista radical, isto é, está interessada na experiência e nas inúmeras conexões 
reveladas no processo construtivo. Argumenta que é necessário mapear os cenários de dramatização que compõem uma obra, e que o pesquisador deve se atentar, sobretudo, ao insignificante, ao detalhe e ao banal. Para ela, nenhum prédio ou cidade pode ser compreendido sem controvérsias. O pesquisador deve, segundo Yaneva, escutar os atores e observar as práticas e procedimentos e como compartilham e decidem entre si (além do diálogo com objetos e técnicas) as decisões construtivas. Com isso, pretende retirar a arquitetura da morfologia da definição e coloca-a na ação: uma maneira de fazer, um tipo de conector, uma atividade.

Yaneva defende que a arquitetura (assim como o urbanismo e o design) não pode ser reduzida a outras explicações, sobretudo a sociológica, pois ela é real em si: tem atores, corpos, máquinas, tecnologias e formas de agrupá-los. As construções de edifícios, bairros e objetos são executadas por meio de constantes hesitações, testes e traduções irredutíveis ao "social". É importante notar que Yaneva não defende que a arquitetura seja autônoma, mas sim inédita (no sentido que sua definição é pós-analítica), pois é na heterogeneidade das associações e das controvérsias que se dá a dimensão do social e da arquitetura. O social não explica nada, é o resultado de um bom mapeamento, e o seu significado é alterado no decorrer da controvérsia. A arquitetura, para a autora, é um meio de criar conexões que trazem os humanos juntos de forma duradora, um tipo de conector "não-social" que desfaz a hegemonia do possível por trás do real ou do mundo simbólico por trás do objetivo.

Yaneva inclui o tempo como dimensão fundamental do estudo da arquitetura, ou seja, as mudanças das misturas que compõem os edifícios depois de prontos. Por isso, recusa estilos, princípios e linguagens, pois, segundo ela, a qualidade (ou ontologia) da arquitetura se inaugura na experiência. Prédios não expressam uma realidade social, mas estão em movimento. Assim, redistribuições de significados são inerentes a cada construção, por isso, para a autora, a arquitetura é radicalmente política, pois é resultado de inúmeras articulações e tensões. O prédio (assim como a cidade) não é um espaço neutro que possibilita a coexistência, tampouco um objeto estático, mas sim age, elabora seu tempo e espaço e é disputado pelos outros interessados. Daí surge o caráter revolucionário e potente da arquitetura, pois pode recompor mundos comuns e alterar a ordem das coisas.

\footnotetext{
${ }^{1}$ Bourdieu, Pierre. "La maison Kabyle ou le monde renversé". In Poulllon, Jean e Maranda, Pierre. Échanges et communications - mélanges offertes à Claude Lévi-Strauss à l'occasion de son 60é anniversaire. Paris, Haye
} 
Mouton, 1970, p. 739-758.

${ }^{2}$ Latour, Bruno. “Not the Question”. Anthropology News, 37(3): 1-5, 1996.

${ }^{3}$ FOUCAUlt, Michel. Surveiller et Punir. Naissance de la prison. Paris, Gallimard, 1975.

${ }^{4}$ LATOUR, Bruno e YANEVA, Albena. "Give me a gun and I will make all buildings move: An ANT's view of architecture”. In GEISER, Reto (org.), Explorations in Architecture: Teaching, desing, research (the official Swiss contribution to the $11^{\text {th }}$ International Architecture Exhibition in Venice, 2008). Basel, Boston, Berlin, Birkhäuser, 2008.

${ }^{5}$ Latour, Bruno. Reassembing the Social. Oxford, Oxford University Press, 2005.

${ }^{6}$ CALlON, Michel. "Le travail de conception en architecture". Situations e Cabiers de la recherché architecturale, 37(1): 25-35, 1996. 